\title{
Antitumor effects of baicalin on ovarian cancer cells through induction of cell apoptosis and inhibition of cell migration in vitro
}

\author{
CHEN GAO, YINGLU ZHOU, HUATAO LI, XIA CONG, ZHONGLING JIANG, \\ XIN WANG, RONGFENG CAO and WENRU TIAN
}

College of Animal Science and Veterinary Medicine, Qingdao Agricultural University, Qingdao, Shandong 266109, P.R. China

Received July 25, 2016; Accepted August 14, 2017

DOI: $10.3892 / \mathrm{mmr} .2017 .7757$

\begin{abstract}
Baicalin, an active flavone isolated from Scutellariabaicalensis Georgi, has been demonstrated to induce various beneficial biochemical effects such as anti-inflammatory, anti-viral, and antitumor effects. However, the antitumor mechanism of baicalin is not well understood. In the present study, baicalin was demonstrated to inhibit the viability and migration of a widely used ovarian cancer cell line, A2780, in a dose-dependent manner. MTT assays revealed that cell viability significantly decreased in ovarian cancer cells treated with baicalin compared with untreated cells, without effect on normal ovarian cells. Flow cytometric analysis indicated that baicalin suppressed cell proliferation by inducing apoptosis. The underlying mechanisms involved were indicated to be downregulation of the anti-apoptotic protein B-cell lymphoma 2 apoptosis regulator and activation of caspase-3 and -9. In addition, wound healing and transwell assays revealed that cell migratory potential and expression of matrix metallopeptidase (MMP)-2 and MMP-9 were significantly inhibited when cells were exposed to baicalin, compared with untreated cells. The present study therefore suggested that baicalin has the potential to be used in novel anti-cancer therapeutic formulations for treatment of ovarian cancer.
\end{abstract}

\section{Introduction}

Ovarian cancer is the most lethal gynecologic cancer (1): The five-year survival rate of patients is $<50 \%$ post diagnosis (2). First-line clinical treatments for ovarian cancer patients are cytoreductive surgery and paclitaxel-based chemotherapy (3). However, because of multi-drug resistance to chemotherapy,

Correspondence to: Dr Huatao Li or Professor Wenru Tian, College of Animal Science and Veterinary Medicine, Qingdao Agricultural University, 700 Changcheng Road, Qingdao, Shandong 266109, P.R. China

E-mail: huataoli@foxmail.com

E-mail:wrtian@126.com

Key words: baicalin, antitumor effect, ovarian cancer, apoptosis, migration systemic chemotherapy produces a disappointingly low initial response in most patients (4). Furthermore, many commonly used anti-cancer chemotherapeutics have potent cytotoxic effects in normal cells (5). Therefore, there is an urgent need to develop effective, non-cytotoxic, chemotherapeutic approaches for patients with ovarian cancer.

In recent years, many bioactive phytochemicals have been observed to exhibit anti-cancer activities $(6,7)$. They demonstrate minimal general toxicity and adverse side effects and thus may represent potential alternative medicine to conventional cytotoxic chemotherapy $(8,9)$. Baicalin is a flavone glycoside found in Scutellaria baicalensis Georgi, with a chemical formula of $\mathrm{C}_{21} \mathrm{H}_{18} \mathrm{O}_{11}$ (10). Baicalin has been reported to have anti-oxidation, anti-proliferation, anti-inflammation and antitumor effects (11-13). With respect to cancer, it has been reported to inhibit the proliferation of various cancer cells through induction of apoptosis and inhibition of migration (14-16). However, the effects of baicalin on ovarian cancer cells and the underlying molecular mechanisms are still not clear.

The present study aimed to evaluate whether baicalin could exert antitumor effects on ovarian cancer cells and to explore the molecular mechanism of this process. The data revealed that baicalin dose-dependently induced apoptosis and significantly reduced the migration of ovarian cancer cells. Baicalin may, therefore, be an effective active ingredient for the development of an effective drug for patients with ovarian cancer.

\section{Materials and methods}

Materials, reagents and chemicals. Antibodiesagainstcaspase-3 (cat. no. 19677-1-AP), caspase-9 (cat. no. 10,380-1-AP), B-cell lymphoma 2 apoptosis regulator (Bcl-2) (cat. no. 12789-1-AP), matrix metallopeptidase (MMP)-2 (cat. no 10373-2-AP), MMP-9 (cat. no. 10375-1-AP) and $\beta$-actin (cat. no. 20,536-1-AP) were obtained from ProteinTech Group, Inc. (Chicago, IL, USA). Secondary polyclonal anti-rabbit horseradish peroxidase (HRP)-conjugated antibodies (cat. no. 111-035-003) were purchased from Jackson ImmunoResearch Laboratories, Inc. (West Grove, PA, USA). Radioimmunoprecipitation assay (RIPA) lysis buffer (50 mM Tris pH 7.4, $150 \mathrm{mM} \mathrm{NaCl,} \mathrm{1 \%}$ NP-40, $0.5 \%$ sodium deoxycholate, $0.1 \%$ SDS, sodium fluoride and EDTA) was from Beyotime Institute of Biotechnology (Haimen, China). The enhanced chemiluminescence (ECL) 
kit was from GE Healthcare Life Sciences (Little Chalfont, UK). The Annexin V-conjugated fluorescein isothiocyanate (FITC) apoptosis detection kit with propidium iodide (PI) was purchased from Nanjing KeyGen Biotech Co., Ltd. (Nanjing, China). Transwells were from BD Biosciences (San Jose, American). MTT (3-(4, 5-dimethyl-2-yl)-2, 5-diphenyl tetrazolium bromide) and DAPI were obtained from Sigma-Aldrich; Merck KGaA (Darmstadt, Germany). Baicalin (concentration $\geq 98 \%$ ) was bought from the National Pharmaceutical Engineering Center (Jiangxi, China).

Drug preparation. Baicalin was dissolved in $100 \%$ DMSO at a concentration of $1 \mathrm{M}$ as a stock solution and stored at $4^{\circ} \mathrm{C}$, and diluted in Dulbecco's modified Eagle's medium (DMEM; Gibco; Thermo Fisher Scientific, Inc., Waltham, MA, USA) to the required concentration before each experiment. The final concentration of DMSO was $<0.1 \%$ in all baicalin groups.

Cell lines and cell culture. The ovarian cancer cell line A2780 and normal ovarian cell line IOSE80 were purchased from American Type Culture Collection (Manassas, VA, USA) and cultured in DMEM medium supplemented with $10 \%$ fetal bovine serum (FBS; Gibco; Thermo Fisher Scientific, Inc.) and $100 \mathrm{U} / \mathrm{ml}$ penicillin (Gibco; Thermo Fisher Scientific, Inc.) at $37^{\circ} \mathrm{C}$ in a humidified atmosphere with $5 \% \mathrm{CO}_{2}$.

Cell viability assays. The effect of baicalin on the viability of cells was detected by MTT assay. The cells $\left(1 \times 10^{4}\right.$ cells/well $)$ were seeded into 96-well plates and incubated for $24 \mathrm{~h}$. Following 24 h treatment with 0 (control) 40, 80, 120, 160, 200 and $240 \mu \mathrm{M}$ baicalin, cell viability was detected by adding $20 \mu 1$ of MTT solution ( $5 \mathrm{mg} / \mathrm{ml}$ in PBS) to each well and incubating the mixtures for $4 \mathrm{~h}$ at $37^{\circ} \mathrm{C}$. The MTT solution was then removed and $150 \mu \mathrm{l}$ of dimethyl sulfoxide (DMSO) was added to the wells. The absorbance was measured using a Multiskan Ascent plate reader (Thermo Fisher Scientific, Inc.) at a wavelength of $540 \mathrm{~nm}$.

DAPI staining assay. To assess the effect of baicalin on the nuclei of ovarian cancer cells, $\sim 4 \times 10^{4}$ cells/well were treated with baicalin at 0,80 or $160 \mu \mathrm{M}$ for $24 \mathrm{~h}$. Cells in each well were then stained with DAPI before fixation with $3.7 \%$ formaldehyde at room temperature for $15 \mathrm{~min}$. The cells were then washed with PBS and detected by fluorescence microscopy. From each sample, 3 visual fields were randomly selected for evaluation.

Cell apoptosis by flow cytometry. The extent of apoptosis was evaluated by flow cytometry using an Annexin V-FITC/PI apoptosis detection kit (cat. no. CA1020, Solarbio, Beijing, China). Following treatment with either 0,80 or $160 \mu \mathrm{M}$ baicalin for $24 \mathrm{~h}$, ovarian cancer cells $\left(1 \times 10^{6}\right.$ cells/well) were harvested and washed thrice with PBS, then incubated with Annexin V-FITC and PI at room temperature for $10 \mathrm{~min}$ in the dark. The cells were detected using a BD Accuri ${ }^{\mathrm{TM}}$ C6 flow cytometer and analyzed using BD Accuri ${ }^{\mathrm{TM}}$ C6 Software version 1.0.264.21 (BD Biosciences, Franklin Lakes, NJ, USA).

Wound healing assays. A2780 cells ( $1 \times 10^{5}$ cells/well) were seeded into 24-well plates and scraped with the end of $200 \mu \mathrm{l}$ pipette tips. The plates were washed with PBS to remove detached cells and then incubated with the complete growth medium containing either 0,20 or $40 \mu \mathrm{M}$ baicalin solution for $24 \mathrm{~h}$. Cell migration was observed under a phase-contrast microscope at 100x magnification at 0 and $24 \mathrm{~h}$ post-induction of injury. Migrated cells in the denuded area in each of six random fields were measured and quantified using Image $\mathbf{J}$ software version 1.50 (National Institutes of Health, Bethesda, MD, USA).

Transwell migration assays. Cell migration was quantified by transwell assays. Ovarian cancer cells were treated with 0,20 or $40 \mu \mathrm{M}$ baicalin for $24 \mathrm{~h}$ and harvested. A total of $2 \times 10^{4}$ cells in serum-free DMEM were added to each upper chamber and DMEM medium with $10 \%$ FBS was added to the lower chamber as a chemoattractant. After $24 \mathrm{~h}$ incubation at $37^{\circ} \mathrm{C}$, cells remaining on the upper surface of membrane were removed and the cells that had migrated to the underside of the membrane were stained with $0.1 \%$ crystal violet for $10 \mathrm{~min}$. The migrated cells on the underside of the membrane were counted under a light microscope under a 200x magnification field. A total of 6 random fields of each transwell membrane were counted and averaged.

Western blot analysis. Total protein was extracted from the cells samples using RIPA lysis buffer (Beyotime Institute of Biotechnology) with protease inhibitors (Biocolor Ltd., Beijing, China) in a proportion of 1:100. Keep on ice for $5 \mathrm{~min}$, swirling the plate occasionally for uniform spreading. Centrifuge samples at $4^{\circ} \mathrm{C}, 12,000 \mathrm{x}$ g for $15 \mathrm{~min}$, transfer supernatant for further analysis. Equal amounts of protein $(25 \mu \mathrm{g})$ were loaded on a $10 \%$ SDS-PAGE gel. The lysates were resolved by electrophoresis $(80 \mathrm{~V}$ for $30 \mathrm{~min}$ and $120 \mathrm{~V}$ for $1.5 \mathrm{~h}$ ) and transferred onto polyvinylidene difluoride membranes (Bio-Rad Laboratories, Inc., Hercules, CA, USA). Membranes were blocked in 5\% nonfat milk for $1 \mathrm{~h}$ at room temperature and then incubated with primary antibodies against caspase $3(1: 1,000)$, caspase $9(1: 1,000)$, Bcl-2 (1:1,000), MMP-2 (1:200), MMP-9 (1:200) or $\beta$-actin $(1: 1,000)$ in blocking buffer overnight at $4^{\circ} \mathrm{C}$. This was followed by incubation with relevant secondary polyclonal anti-rabbit HRP-conjugated antibody $(1: 5,000)$ for $1 \mathrm{~h}$ at room temperature. Protein bands were visualized using a Chemiluminescent ECL assay kit (GE Healthcare Life Sciences) and the Bio-Rad ChemiDoc XRS+ image analyzer. Protein expression levels were quantitatively determined using Image J software version 1.50 (National Institutes of Health, Bethesda, MD, USA). $\beta$-actin was used as internal reference for protein expression in the treated cells.

Statistical analysis. Data are presented as the mean \pm standard deviation of 3 independent experiments. For each independent experiment, the assays were performed in duplicate. Statistical differences between two groups were analyzed using a Student's t-test and multiple comparison analyses were performed by one-way analysis of variance followed by Tukey post-hoc testing. Statistical analysis was performed using GraphPad Prism 5.0 (GraphPad Software, Inc., La Jolla, CA, USA). $\mathrm{P}<0.05$ was considered to indicate a statistically significant difference. 
A

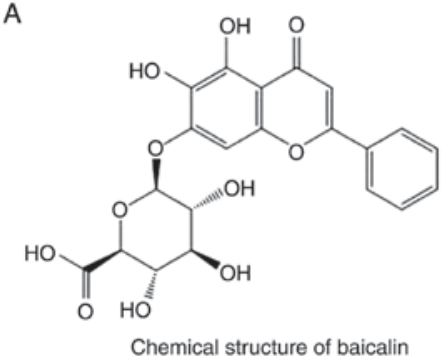

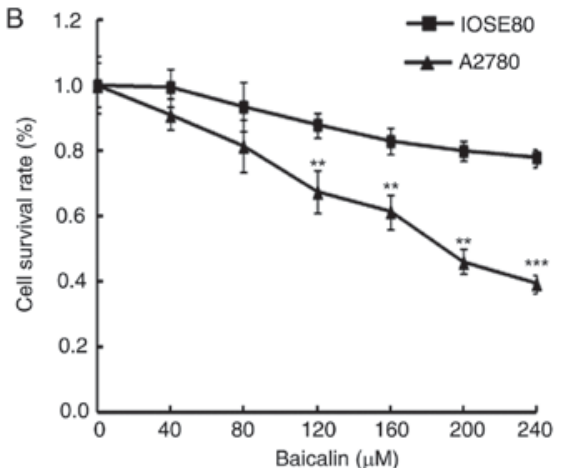

Figure 1. Effects of baicalin on ovarian cancer cell and normal ovarian cell viability. (A) Chemical structure of baicalin. (B) Viability of A2780 ovarian cancer cells and IOSE80 normal ovarian cells was determined by MTT assay following treatment with 0,40,80,120, 160, 200 or $240 \mu \mathrm{M}$ baicalin for $24 \mathrm{~h}$. Data are presented as the mean \pm standard deviation of 3 replicates. ${ }^{* *} \mathrm{P}<0.01$ and ${ }^{* * * *} \mathrm{P}<0.001$ vs. the $0 \mu \mathrm{M}$ control group.
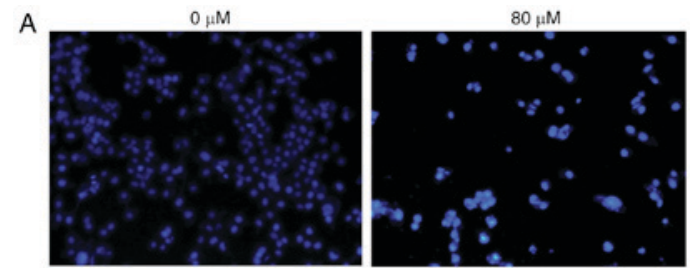

B

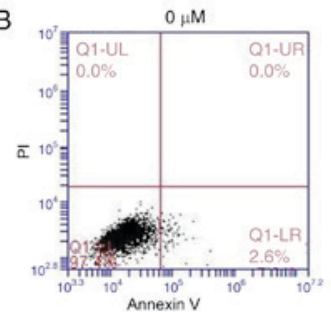

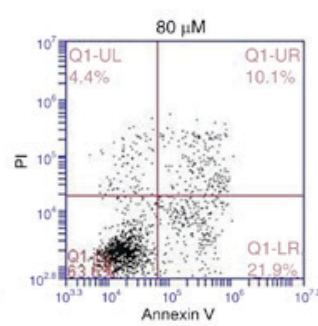
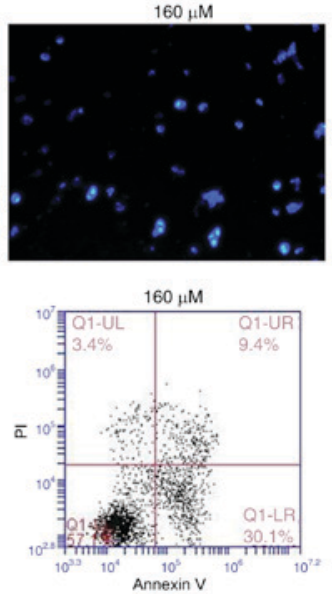

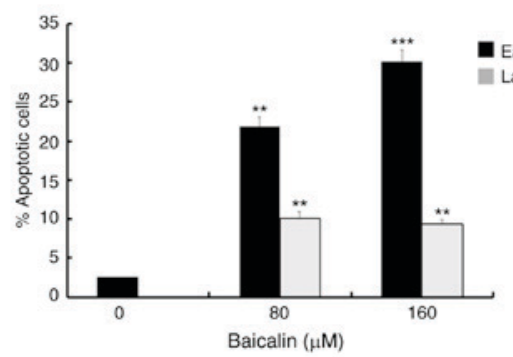

Figure 2. Baicalin induces apoptosis in A2780 ovarian cancer cells. (A) Cell nucleus morphology in cells treated with 0,80 or $160 \mu \mathrm{M}$ baicalin was observed by DAPI staining (original magnification, x100). (B) Apoptosis was detected by Annexin V/PI staining following treatment with 0,80 or $160 \mu \mathrm{M}$ baicalin. Early apoptotic cells (Annexin $\mathrm{V}^{+} / \mathrm{PI}^{-}$) are shown in the lower right quadrant of the chart, while the upper right quadrant indicates late apoptotic cells (Annexin $\mathrm{V}^{+} / \mathrm{PI}^{+}$). Quantitative data are presented as the mean \pm standard deviation of 3 replicates. ${ }^{* *} \mathrm{P}<0.01$ and ${ }^{* * * *} \mathrm{P}<0.001$ vs. the $0 \mu \mathrm{M}$ control group. $\mathrm{PI}$, propidium iodide.

\section{Results}

Baicalin inhibits ovarian cancer cell viability. In order to determine the effects of baicalin (Fig. 1A) on the viability of A2780 ovarian cancer cells and IOSE80 normal ovarian cells, cells were treated with $0,40,80,120,160,200$ and $240 \mu \mathrm{M}$ baicalin for $24 \mathrm{~h}$, then cell viability was determined by MTT assay. Cancer cells treated with baicalin revealed significantly reduced viability compared with untreated cells, in a dose-dependent manner (Fig. 1B). However, baicalin did not affect the growth of normal ovarian cells (Fig. 1B). These data therefore indicated that baicalin inhibited the growth of ovarian cancer cells.
Baicalin induces ovarian cancer cell apoptosis. To assess whether the antitumor effects of baicalin on A2780 ovarian cancer cells were associated with apoptosis, cells were stained with DAPI and observed under a fluorescence microscope (Fig. 2A). Nuclear chromatin condensation and fragmented punctuate blue nuclear fluorescence were observed in ovarian cancer cells treated with 80 and $160 \mu \mathrm{M}$ baicalin for $24 \mathrm{~h}$, in a dose-dependent manner, while the control cells displayed normal and intact nuclei. This suggested that baicalin may induce ovarian cancer cell apoptosis. To further investigate this, apoptosis was analyzed by flow cytometry (Fig. 2B). The parentage of early- and late-stage apoptotic cells significantly increased in groups treated with baicalin compared 

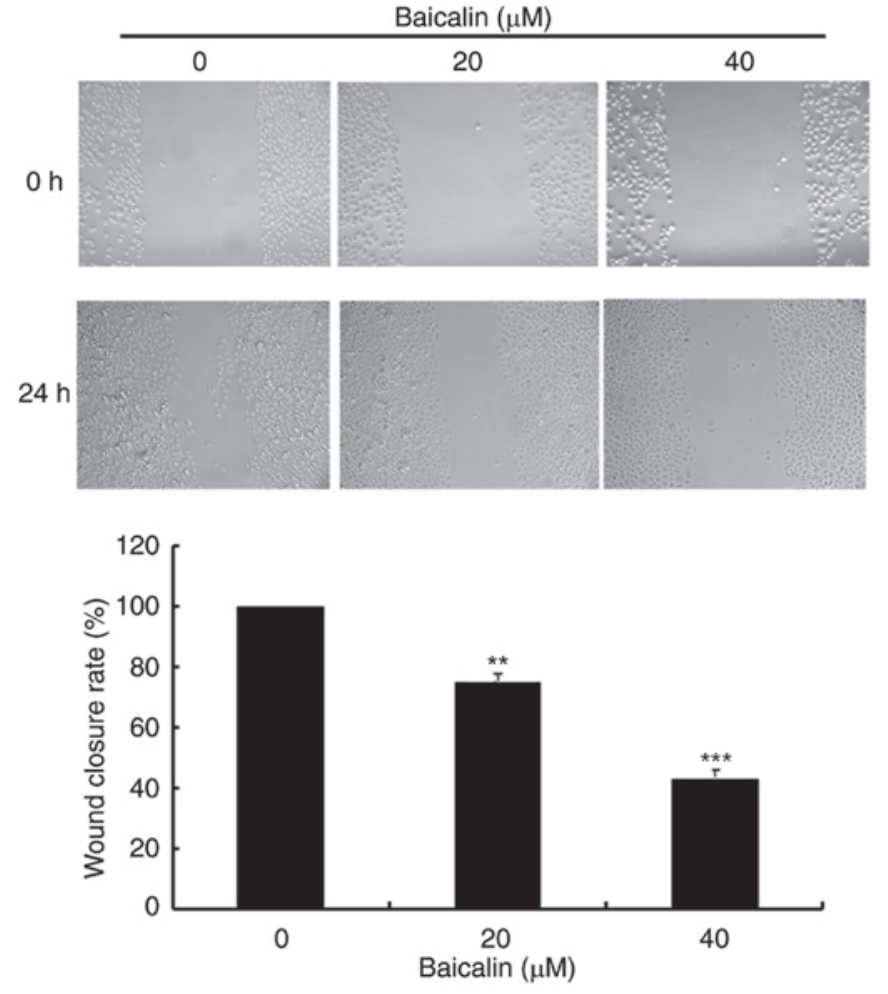

Figure 3. Effects of baicalin on A2780 ovarian cancer cell migration, assessed by wound healing assay. Cells were scraped with a pipette tip and treated with 0,20 or $40 \mu \mathrm{M}$ baicalin for $24 \mathrm{~h}$. Cells were imaged under a light microscope (original magnification, x100) before and after injury. Cell migration was quantified by measuring wound closure areas before and after injury. Quantitative data are presented as the mean \pm standard deviation of 3 replicates. ${ }^{* *} \mathrm{P}<0.01$ and ${ }^{* * * *} \mathrm{P}<0.001$ vs. the $0 \mu \mathrm{M}$ control group.

with untreated control cells (Fig. 2B): The percentage of total apoptotic A2780 cells was $2.6 \%$ in the control cells $(2.6 \%$ early-stage and $0 \%$ late-stage), $32 \%$ in the cells treated with $80 \mu \mathrm{M}$ baicalin (21.9\% early-stage and $10.9 \%$ late-stage) and $39.5 \%$ in the cells treated with $160 \mu \mathrm{M}$ baicalin $(30.1 \%$ early-stage and $9.4 \%$ late-stage). These results demonstrated that baicalin induces apoptosis in A2780 ovarian cancer cells.

Baicalin suppresses migration of ovarian cancer cells by antagonizing MMP-9 expression. To evaluate the effects of baicalin on cell migration, wound healing assays and transwell assays were performed. In the wound healing assay, baicalin dose-dependently significantly decreased the migration of A2780 cells compared with the untreated control (Fig. 3). Likewise, baicalin significantly inhibited ovarian cancer cell migration in a $24 \mathrm{~h}$ transwell assay, in a dose-dependent manner, compared with untreated control cells (Fig. 4). Treatment with 20 and $40 \mu \mathrm{M}$ baicalin inhibited A2780 cells migration by 59 and $87 \%$ respectively $(\mathrm{P}<0.001$; Fig. 4). The wound healing and transwell chamber assays both suggested that baicalin suppresses the migration of ovarian cancer cells. Given the effects of baicalin on ovarian cancer cell migration, the mechanisms of this process were further investigated. Since MMPs plays an important role in cancer metastasis, MMP-2 and MMP-9 protein expression levels were detected by western blot. Baicalin dose-dependently reduced MMP-2 and MMP-9 protein expression levels in
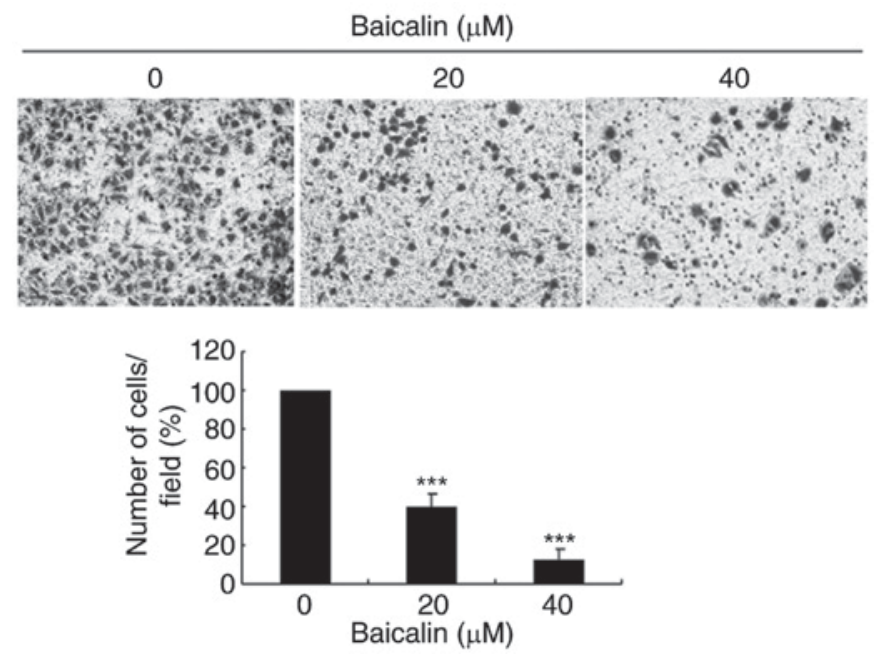

Figure 4. Effects of baicalin on A2780 ovarian cancer cell migration, assessed by transwell assay. Cells were treated. Images represent cell migration to the underside of transwell membranes following treatment with 0,20 or $40 \mu \mathrm{M}$ baicalin for $24 \mathrm{~h}$ (original magnification, $\mathrm{x} 200$ ). Quantitative data are presented as the mean \pm standard deviation of 3 replicates, relative to the $0 \mu \mathrm{M}$ control group. ${ }^{* *} \mathrm{P}<0.01$ and ${ }^{* * *} \mathrm{P}<0.001$ vs. the $0 \mu \mathrm{M}$ control group.

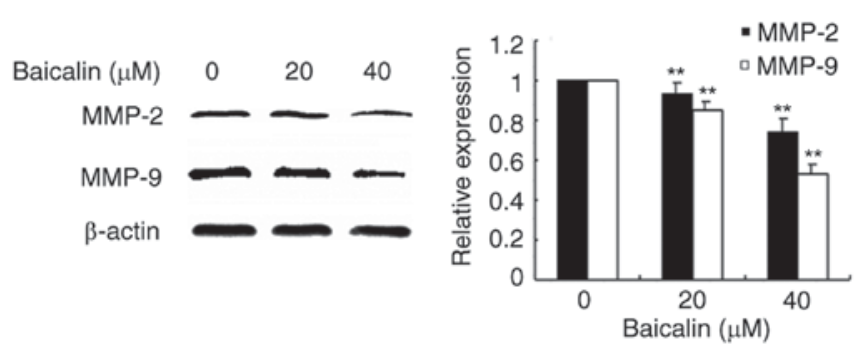

Figure 5. Effects of baicalin on protein expression levels of MMP-2 and -9. Protein expression levels of MMP-9 and MMP-2 were assessed by western blotting analysis following treatment with 0,20 or $40 \mu \mathrm{M}$ baicalin for $24 \mathrm{~h}$. $\beta$-actin served as a loading control. Quantitative data are presented as the mean \pm standard deviation of 3 replicates. ${ }^{* *} \mathrm{P}<0.01$ vs. the $0 \mu \mathrm{M}$ control group. MMP, matrix metallopeptidase.

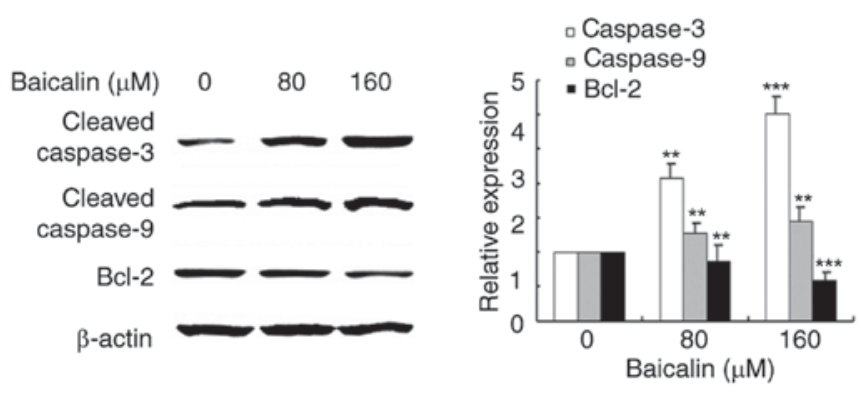

Figure 6. Effects of baicalin on protein expression levels of apoptosis-related proteins. Protein expression levels of cleaved caspase-3, cleaved caspase- 9 and $\mathrm{Bcl}-2$, were assessed by western blotting analysis following treatment with 0,80 or $160 \mu \mathrm{M}$ baicalin for $24 \mathrm{~h}$. $\beta$-actin served as a loading control. Quantitative data are presented as the mean \pm standard deviation of 3 replicates. ${ }^{* *} \mathrm{P}<0.01$ and ${ }^{* * *} \mathrm{P}<0.001$ vs. the $0 \mu \mathrm{M}$ control group. Bcl-2, B-cell lymphoma 2 apoptosis regulator.

treated cells compared with untreated cells (Fig. 5). These data therefore suggested that the inhibitory effect of baicalin on the migration of ovarian cancer was at least partially 
associated with downregulation of MMP-2 and MMP-9 expression.

The effects of baicalin on apoptosis-related proteins. Since baicalin was demonstrated to induce apoptosis in ovarian cancer cells, the expression and activation of apoptosis related proteins was investigated by western blotting analysis (Fig. 6). Protein expression levels of $\mathrm{Bcl}-2$, an anti-apoptotic protein, decreased in ovarian cancer cells treated with baicalin in a dose-dependent manner, compared with untreated control cells. Cleavage of caspase- 3 and caspase- 9 was also measured in the study: The results revealed that cleaved-caspase- 3 and cleaved-caspase-9 levels increased in baicalin-treated ovarian cancer cells compared with untreated control cells. These results suggested that baicalin may activate the caspase-dependent apoptosis pathway in A2780 cells.

\section{Discussion}

Apoptosis is a fundamental life phenomenon through the whole process of life (17). It has been reported that in many human tumor cells, the proliferation of cells is unrestricted if cells apoptosis is definitely hindered (18). Therefore, the antitumor effects of baicalin on ovarian cancer cells was investigated as a strategy to identify new and effective drugs for patients with ovarian cancer. Baicalin has previously been demonstrated to inhibit platelet-derived growth factor-BB-stimulated vascular smooth muscle cell proliferation through suppressing $\beta$-type platelet-derived growth factor receptor/extracellular signal-regulated kinase signaling (19). Baicalin, a phytochemical component of Scutellaria baicalensis Georgi has widespread applications as anti-inflammatory, anti-hepatitis and anti-oxidation agent $(11,20,21)$. Furthermore, the anti-cancer effect of baicalin has also been previously documented (22). The present study aimed to explore the effects of baicalin on ovarian cancer cells and analyze the mechanisms underlining the observed effects.

Monomer compounds extracted from plants have previously been reported to induce apoptosis (23-25). Apoptosis is programmed cell death and plays a vital role in eliminating mutated or hyper-growing cancer cells. Various natural compounds have been shown to suppress the growth of tumor cells by inducing apoptosis (26-28). Therefore, induction of apoptosis has become the major target of most anti-cancer agents. It has been reported that baicalin inhibits the proliferation of HeLa cells via the induction of apoptosis through the intracellular mitochondrial pathway (29). The present study indicated that baicalin significantly reduces the viability of ovarian cancer cells, with no significant effect observed in normal ovarian cells, and that ovarian cancer cells treated with baicalin displayed specific apoptotic morphological changes. In addition, the percentage of early and late apoptotic ovarian cancer cells significantly increased following treatment with baicalin. Thus, baicalin may specifically and significantly induce apoptosis of ovarian cancer cells without affecting normal ovarian cells. Mitochondrial proteins directly activate cellular apoptotic programs $(30,31)$. Bcl-2 is involved in the mitochondria-associated apoptotic pathway (32). Downregulation of Bcl-2 expression could lead to loss of mitochondrial membrane potential and trigger a series of apoptotic events such as activation of caspase-9 and caspase-3, as observed in this study. Peng et al (29) indicated that baicalin-induces apoptosis in HeLa cells through activation of caspase-3 through the intracellular mitochondrial pathway and the surface death receptor pathway, however, it did not show that baicalin could suppress migration of ovarian cancer cells by antagonizing MMP2/9 expression. The present study demonstrated that baicalin not only induced ovarian cancer cell apoptosis via the intracellular mitochondrial pathway but also suppressed they migratory ability of ovarian cancer cells by antagonizing MMP2/9 expression. These data suggested that baicalin could induce cell death through the mitochondria-associated apoptotic pathway in A2780 epithelial ovarian cancer cells, but requires further confirmation in other cell models of ovarian cancer.

Additionally, the present study demonstrated that baicalin effectively suppressed ovarian cancer cell migration. MMP-9 and MMP-2 belong to the gelatin enzyme class of proteases $(33,34)$. A recent study has suggested that the expression of MMP-9 is associated with metastasis in ovarian cancer (35). Also, the inhibition of MMP-2 expression suppresses the metastatic potential of prostate cancer cells (36). The present study demonstrated that baicalin significantly inhibited ovarian cancer cell migration and that MMP-9 and MMP-2 protein expression was reduced by baicalin treatment in a dose-dependent manner. These findings indicate that baicalin may suppress ovarian cancer cell migration through downregulation of MMP-9 and MMP-2 expression.

In conclusion, to the best of our knowledge, the present study is the first to demonstrate that baicalin may function as a selective antitumor agent for ovarian cancer by inhibiting cell viability, inducing apoptosis and suppressing ovarian cancer cell migration. These data thus suggested that baicalin may potentially be used in the formulation of a novel and effective antitumor treatment for ovarian cancer patients.

\section{Acknowledgements}

We are grateful to Professor Nazir Ahmad from the University of Agriculture, Faisalabad, Pakistan for detailed correction of the manuscript. The present study was supported by grants from the National Natural Science Foundation of China (grant nos. 31572590, 31772815 and 31502138), Shandong Province (grant no. BS2015NY001), and Higher Educational Science and Technology Program of Shandong Province (grant no. J15LF03).

\section{References}

1. Temkin SM, Tanner EJ, Dewdney SB and Minasian LM: Reducing overtreatment in gynecologic oncology: The case for less in endometrial and ovarian cancer. Front Oncol 6: 118, 2016.

2. Vernooij F, Heintz P, Witteveen E and van der Graaf Y: The outcomes of ovarian cancer treatment are better when provided by gynecologic oncologists and in specialized hospitals: A systematic review. Gynecol Oncol 105: 801-812, 2007.

3. Markman M: Current status and future directions of platinum/paclitaxel-based chemotherapy of ovarian cancer. Semin Oncol 24 (4 Suppl 11): S11-S27, 1997.

4. Fujiwara Y, Takaishi K, Nakao J, Ikeda T, Katabuchi H, Takeya M and Komohara Y: Corosolic acid enhances the antitumor effects of chemotherapy on epithelial ovarian cancer by inhibiting signal transducer and activator of transcription 3 signaling. Oncol Lett 6: 1619-1623, 2013. 
5. Roy J, Maltais R, Jegham $\mathrm{H}$ and Poirier D: Libraries of $2 \beta$-(N-substituted piperazino)-5 $\alpha$-androstane-3 $\alpha, 17 \beta$-diols: Chemical synthesis and cytotoxic effects on human leukemia HL-60 cells and on normal lymphocytes. Mol Divers 15: 317-339, 2011.

6. Zhou L, Xu T, Zhang Y, Zhu M, Zhu W, Wang Z, Gu H, Wang H, Li P, Ying J, et al: Transcriptional network in ovarian cancer cell line SKOV3 treated with Pinellia pedatisecta Schott extract. Oncol Rep 36: 462-470, 2016.

7. Yung MM, Ross FA, Hardie DG, Leung TH1, Zhan J, Ngan HY and Chan DW: Bitter Melon (Momordica charantia) extract inhibits tumorigenicity and overcomes cisplatin-resistance in ovarian cancer cells through targeting AMPK signaling cascade. Integr Cancer Ther 15: 376-389, 2016

8. Ahmed KM: The effect of olive leaf extract in decreasing the expression of two pro-inflammatory cytokines in patients receiving chemotherapy for cancer. A randomized clinical trial. Saudi Dent J 25: 141-147, 2013.

9. Zhang HB, Lu P, Cao WB, Zhang ZH and Meng XL: The effect-enhancing and toxicity-reducing activity of Hypericum japonicum Thunb. Extract in murine liver cancer chemotherapy. Mol Clin Oncol 1: 395-399, 2013.

10. Wang CZ, Zhang CF, Chen L, Anderson S, Lu F and Yuan CS: Colon cancer chemopreventive effects of baicalein, an active enteric microbiome metabolite from baicalin. Int J Oncol 47: 1749-1758, 2015.

11. Guo X, Chi S, Cong X, Li H, Jiang Z, Cao R and Tian W: Baicalin protects sertoli cells from heat stress-induced apoptosis via activation of the Fas/FasL pathway and Hsp72 expression. Reprod Toxicol 57: 196-203, 2015.

12. Sun SJ, Wu XP, Song HL and Li GQ: Baicalin ameliorates isoproterenol-induced acute myocardial infarction through iNOS, inflammation, oxidative stress and P38MAPK pathway in rat. Int J Clin Exp Med 8: 22063-22072, 2015.

13. Yu Y, Pei M and Li L: Baicalin induces apoptosis in hepatic cancer cells in vitro and suppresses tumor growth in vivo. Int J Clin Exp Med 8: 8958-8967, 2015.

14. Cortés-Castell E, Veciana-Galindo C, Torró-Montell L, Palazón-Bru A, Sirvent-Segura E, Gil-Guillén V and Rizo-Baeza M: Protection by polyphenol extract from olive stones against apoptosis produced by oxidative stress in human neuroblastoma cells. Nutr Hosp 33: 118-122, 2016.

15. Kim GT, Lee SH and Kim YM: Torilis japonica extract-generated intracellular ROS induces apoptosis by reducing the mitochondrial membrane potential via regulation of the AMPK-p38 MAPK signaling pathway in HCT116 colon cancer. Int J Oncol 49: 1088-1098, 2016.

16. Hwang S, Cho GS, Ryu S, Kim HJ, Song HY, Yune TY, Ju C and Kim WK: Post-ischemic treatment of WIB801C, standardized Cordyceps extract, reduces cerebral ischemic injury via inhibition of inflammatory cell migration. J Ethnopharmacol 186: 169-180, 2016.

17. Afford S and Randhawa S: Apoptosis. Mol Pathol 53: 55-63, 2000.

18. Martin SJ, Lennon SV, Bonham AM and Cotter TG: Induction of apoptosis (programmed cell death) in human leukemic HL-60 cells by inhibition of RNA or protein synthesis. J Immunol 145 : 1859-1867, 1990

19. Dong LH, Wen JK, Miao SB, Jia Z, Hu HJ, Sun RH, Wu Y and Han M: Baicalin inhibits PDGF-BB-stimulated vascular smooth muscle cell proliferation through suppressing PDGFRbeta-ERK signaling and increase in p27 accumulation and prevents injury-induced neointimal hyperplasia. Cell Res 20: 1252-1262, 2010.
20. Ye C, Li S, Yao W, Xu L, Qiu Y, Liu Y, Wu Z and Hou Y: The anti-inflammatory effects of baicalin through suppression of NLRP3 inflammasome pathway in LPS-challenged piglet mononuclear phagocytes. Innate Immun 22: 196-204, 2016.

21. Zhao W, Liu L, Wang Y, Mao T and Li J: Effects of a combination of puerarin, baicalin and berberine on the expression of proliferator-activated receptor- $\gamma$ and insulin receptor in a rat model of nonalcoholic fatty liver disease. Exp Ther Med 11: 183-190, 2016.

22. Lange I, Moschny J, Tamanyan K, Khutsishvili M, Atha D, Borris RP and Koomoa DL: Scrophularia orientalis extract induces calcium signaling and apoptosis in neuroblastoma cells. Int J Oncol 48: 1608-1616, 2016.

23. Lee K, Hong S, Seong GJ and Kim CY: Cigarette smoke extract causes injury in primary retinal ganglion cells via apoptosis and autophagy. Curr Eye Res 41: 1367-1372, 2016.

24. Ebrahimzadeh-Bideskan AR, Hami J, Alipour F, Haghir H, Fazel AR and Sadeghi A: Protective effects of ascorbic acid and garlic extract against lead-induced apoptosis in developing rat hippocampus. Metab Brain Dis 31: 1123-1132, 2016.

25. Kim MK, Choi HS, Cho SG, Shin YC and Ko SG: Rubus coreanus Miquel extract causes apoptosis of doxorubicin-resistant NCI/ADR-RES ovarian cancer cells via JNK phosphorylation. Mol Med Rep 13: 4065-4072, 2016.

26. Lin R, Li Z, Lin J, Ye J, Cai Q, Chen L and Peng J: Ethanolic extract of Tulipa edulis Bak induces apoptosis in SGC-7901 human gastric carcinoma cells via the mitochondrial signaling pathway. Oncol Lett 10: 2371-2377, 2015.

27. Listyawati S, Sismindari, Mubarika S, Murti YB and Ikawati M: Anti-proliferative activity and apoptosis induction of an ethanolic extract of boesenbergia pandurata (Roxb.) schlecht. Against HeLa and vero cell lines. Asian Pac J Cancer Prev 17: 183-187, 2016.

28. Wang C and Wang B: Ginkgo biloba extract attenuates oxidative stress and apoptosis in mouse cochlear neural stem cells. Phytother Res 30: 774-780, 2016

29. Peng Y, Fu ZZ, Guo CS, Zhang YX, Di Y, Jiang B and Li QW Effects and mechanism of baicalin on apoptosis of cervical cancer HeLa cells in-vitro. Iran J Pharm Res 14: 251-261, 2015.

30. Liu M, Li SJ, Xin YN, Ji SS, Xie RJ and Xuan SY: Ferric nitrilotriacetate (Fe-NTA)-induced reactive oxidative species protects human hepatic stellate cells from apoptosis by regulating Bcl-2 family proteins and mitochondrial membrane potential. Int J Clin Exp Med 8: 18074-18081, 2015.

31. Dejean LM, Martinez-Caballero S, Manon S and Kinnally KW: Regulation of the mitochondrial apoptosis-induced channel, MAC, by BCL-2 family proteins. Biochim Biophys Acta 1762: 191-201, 2006.

32. Soriano ME and Scorrano L: The interplay between BCL-2 family proteins and mitochondrial morphology in the regulation of apoptosis. Adv Exp Med Biol 687: 97-114, 2010

33. Zhou Y, Zeng YP, Zhou Q, Guan JX and Lu ZN: The effect of captopril on the expression of MMP-9 and the prognosis of neurological function in herpes simplex encephalitis mice. Neurol Res 38: 733-739, 2016

34. Li NA, Wang H, Zhang J and Zhao E: Knockdown of hypoxia inducible factor- $2 \alpha$ inhibits cell invasion via the downregulation of MMP-2 expression in breast cancer cells. Oncol Lett 11: 3743-3748, 2016.

35. Che YL, Luo SJ, Li G, Cheng M, Gao YM, Li XM, Dai JM, He H, Wang J, Peng HJ, et al: The C3G/Rap1 pathway promotes secretion of MMP-2 and MMP-9 and is involved in serous ovarian cancer metastasis. Cancer Lett 359: 241-249, 2015.

36. Liu H, Chen A, Guo F and Yuan L: A short-hairpin RNA targeting osteopontin downregulates MMP-2 and MMP-9 expressions in prostate cancer PC-3 cells. Cancer Lett 295: 27-37, 2010. 